\title{
Peningkatan Kompetensi Dosen PembimbingKlinis Dalam Menyusun Soal OSCE (Objective Structered Clinical Examination)
}

\author{
Surya Akbar ${ }^{1}$, Tezar Samekto Darungan ${ }^{2}$, Halimah Tania ${ }^{3}$ \\ ${ }^{1,2}$ Medical Education Unit, Fakultas Kedokteran, UISU, Medan, Indonesia \\ ${ }^{3}$ Laboratotrium Keterampilan Klinis, Fakultas Kedokteran, UISU, Medan, Indonesia \\ Email: ${ }^{1}$ surya.akbar@fk.uisu.ac.id, ${ }^{2}$ darungantezarsamekto@gmail.com, ${ }^{3}$ hthania@gmail.com
}

\begin{abstract}
This community service is taken in training form. Training is given to clinical supervisors with the aim of increasing the competence of clinical supervisors for evaluating achivement of clerkship in clinical learning process. The training used a four steps method, i.e: namely: determining the level of competence, compiling disease case scenarios, entering disease case scenarios into the OSCE template, completing information related to OSCE and assessment rubric. Using this method, clinical supervisors are proven to be better at composing OSCE questions. The results of this training, there is 7 OSCE questions had made from 7 departments. A review of these questions resulted in two questions that did not match between the level of assessment with the level of competence; one question that has excess time allocation and 2 questions that have less time allocation. In the future, the preparation of OSCE questions must be carried out routinely by clinical supervisors, so that clinical supervisors are used to preparing OSCE questions. The questions collected need to be revised so that they can be used in the OSCE exam.
\end{abstract}

Keywords: Question, OSCE, Writing, Assessment.

\begin{abstract}
Abstrak
Pengabdian masyarakat ini berbentuk pelatihan. Pelatihan diberikan kepada dosen pembimbing klinis dengan tujuan untuk meningkatkan kompetensi seorang dosen pembimbing klinis dalam mengevaluasi hasil belajar mahasiswa di tahap pembelajaran klinis. Pelaksanaan menggunakan metode 4 tahap, yaitu: penentuan level kompetensi, menyusun skenario kasus penyakit, memasukkan skenario kasus penyakit ke template soal OSCE, melengkapi informasi soal OSCE dan rubrik penilaian. Menggunakan metode ini dosen pembimbing klinis terbukti lebih baik dalam menyusun soal OSCE. Hasil dari pelatihan ini terbentuk 7 soal OSCE dari 7 departemen. Review terhadap soal-soal tersebut diperoleh dua soal yang tidak sesuai antara tingkat penilaian dengan level kompetensi; satu soal yang memiliki alokasi waktu yang berlebih dan 2 soal yang memiliki alokasi waktu yang kurang. Kedepannya penyusunan soal OSCE sebaiknya dilakukan secara rutin oleh dosen pembimbing klinis agar terbiasa menyusun soal OSCE. Soal yang terkumpul perlu dilakukan revisi kembali agar dapat digunakan dalam ujian OSCE.
\end{abstract}

Kata Kunci: Soal, OSCE, Penyusunan, Ujian.

\section{A. PENDAHULUAN}

Pembelajaran pada pendidikan dokter tidak berbeda dengan pendidikan pada disiplin ilmu lainnya, dimana pembelajaran berfokus pada 3 domain (Singh \& Singh, 2020), yaitu domain kognitif, psikomotor, dan afektif. Pembelajaran untuk mencapai kompetensi keterampilan klinis dicapai melalui pelatihan keterampilan klinis yang dimulai dari tahap akademik hingga tahap profesi.

Pada domain kognitif, mahasiswa dilatih untuk dapat menguasai tingkat pemahaman sesuai dengan tingkat pengetahuan yang disampaikan oleh Bloom. Tingkat pengetahuan Bloom terdiri atas 6 tingkatan yaitu: mengingat, memahami, mengaplikasi, menganalisis, mengevaluasi, menciptakan (Anderson et al., 2001). Tingkatan pengetahuan tersebut dapat dibagi menjadi dua kategori berdasarkan kedalam proses berpikir yang dilakukan, dimana tingkat pengetahuan mengingat, mengaplikasi dan menganalisis dikelompokkan menjadi pemikiran tingkat rendah (low order thinking), sementara tingkat mengaplikasi, menganalisis dan mengevaluasi dikelompokkan menjadi kategori pemikiran tingkat tinggi (high order thinking) (Tyas et al., 2020). Pemikiran tingkat rendah dapat dicapai melalui proses pengajaran seperti kuliah konvensional, sedangkan untuk membentuk pemikiran tingkat tinggi dapat dicapai 
melalui metode diskusi ataupun project-based learning.

Domain psikomotor memiliki tingkatan penguasaan yang harus dicapai oleh mahasiswa, yaitu tingkat Knows (tahu tentang suatu keterampilan), Knows How (tahu bagaimana melakukannya), Shows How (memperlihatkan bagaimana melakukannya), dan Does (melakukan secara mandiri) (Miller, 1990). Tingkatan tersebut mengharuskan seseorang memiliki pengetahuan tentang dan untuk melakukan suatu keterampilan tertentu, karena pada dasarnya dalam melakukan suatu keterampilan diperlukan integrasi antara pengetahuan dan keterampilan.

Domain afektif memiliki 5 tingkatan dari receiving (menerima), responding (merespon), valuing (memberikan nilai), organization (mengorganisir), characterization (karakteristasi nilai) (Krathwohl et al., 1964). Tingkatan dalam pembelajaran afektif didasarkan pada pembentukan nilai-nilai dalam diri seseorang yang pada akhirnya akan tergambarkan dalam sikap atau perilaku dirinya dalam menghadapi suatu keadaan atau peristiwa tertentu. Pengajaran pada domain afektif dapat dilakukan melalui diskusi, mendengarkan presentasi, ataupun refleksi.

Pendidikan dokter di Indonesia sekarang ini menerapkan Kurikulum Bersasis Kompetensi (KBK) (Konsil Kedokteran Indonesia, 2012b). Kurikulum Berbasis Kompetensi berfokus dalam menghasilkan lulusan yang memiliki kompetensi tertentu yang telah ditetapkan (Dent \& Harden, 2013). Kompetensi adalah seperangkat Standar kompetensi seorang dokter terdiri atas 7 area kompetensi, yaitu (Konsil Kedokteran Indonesia, 2012a): profesionalitas yang luhur, mawas diri dan pengembangan diri, komunikasi efektif, pengelolaan informasi, landasan ilmiah ilmu kedokteran, keterampilan klinis, pengelolaan masalah kesehatan. Pencapaian kompetensi seorang dokter biasa dilakukan melalui dua tahap pendidikan, yaitu tahap pendidikan dokter (akademik) dan tahap profesi dokter (profesi). Kedua tahapan ini saling terkait dalam satu rangkaian pendidikan dokter.

Penilaian kemampuan seorang mahasiswa terhadap penguasaan dari masing-masing domain dapat dilakukan menggunakan metode yang berbedabeda. Penilaian terhadap kemampuan kognitif dan afektif dapat dilakukan melalui ujian tertulis (MCQ, MEQ, Essay, Makalah, Porfolio, dll), sedangkan untuk domain psikomotor dapat dilakukan dengan penilaian DOPS (Direct Observastion of Procedural Skills). Namun, kekurangan dari metode-metode tersebut adalah ketidakmampuan setiap metode untuk menilai integrasi dari pelaksanaan ketiga domain tersebut. Hal ini sesuai dengan definisi kompetensi itu sendiri, dimana kompetensi dapat diartikan sebagai kemampuan yang harus dikuasai oleh seorang dokter yang mencakup pengetahuan, keterampilan dan sikap kerja untuk dapat melaksanakan kegiatan profesionalnya kepada masyarakat secara mandiri (Konsil Kedokteran Indonesia, 2013).

Penilaian menggunakan metode OSCE (Objective Structered Clinical Examination) merupakan metode yang dapat menggambarkan kemampuan kompetensi seorang dokter dalam menjalankan profesinya (Elshama, 2020). Metode penilaian OSCE terdiri atas 12 stasion (ruang ujian) dimana setiap stasion memiliki kasus yang berbeda-beda. Stasion-stasion tersebut dapat disertai atau tanpa disertai pasien standar. Mahasiswa yang mengikuti ujian OSCE diharuskan mengerjakan tugas yang disampaikan di masing-masing stasion tersebut. Secara umum terdapat 8 poin penilaian di masingmasing stasion, yaitu: anamnesis, pemeriksaan fisik, pemeriksaan penujang, diagnosis \& diagnosis banding, penatalaksanaan farmakologi, penatalaksanaan non farmakologi, komunikasi \& edukasi, dan profesionalisme. Setiap stasion memiliki penekanan penilaian berbeda-beda, artinya tidak seluruh stasion memiliki 8 poin penilaian di atas, sehingga seluruh stasion memiliki variasi dalam poin penilaiannya.

Pelaksanaan OSCE merupakan suatu hal yang kompleks, karena melibatkan banyak pihak, alat dan bahan (Khan et al., 2013). Begitu pula dalam hal menyusun soal OSCE, dimana seorang dosen pembimbing klinis harus menyusun soal OSCE yang sesuai dengan standar dan blueprint yang telah ditetapkan. Setiap stasion akan ditulis oleh seorang dosen pembimbing klinis. Penulis soal OSCE harus memastikan soal yang dibuat memenuhi kriteria berikut (Boursicot \& Roberts, 2005): instruksi bagi mahasiswa harus jelas, instruksi bagi penguji harus jelas, daftar kebutuhan alat dan bahan, kebutuhan pasien standar, skenario pasien standar, skills yang diuji, dan lama pelaksaaan ujian di stasion tersebut. Untuk menghindari kesalahan soal yang dibuat, maka setelah soal selesai disusun akan dilanjutkan dengan proses review.

Pelaksanaan OSCE sering digunakan sebagai summative assessment, namun dapat juga digunakan sebagai formative assessment. Penilaian sumatif bertujuan untuk menentukan kelulusan mahasiswa, sedangkan penilaian formatif ditujukan untuk meningkatkan kemampuan mahasiswa. Penilaian kelemahan mahasiswa baik dalam hal clinical reasoning (kognitif) ataupun melakukan suatu keterampilan (skill) merupakan suatu tujuan dari formative assessment dari pelaksanaan OSCE (Patwari et al., 2021). Secara keseluruhan banyak keuntungan yang dapat diperoleh dengan pelaksanaan ujian OSCE. Namun, dosen 
pembimbing klinis yang bertugas untuk menyusun soal OSCE belum memiliki pengetahuan dan keterampilan dalam menyusun soal OSCE.

Berdasarkan penjelasan di atas, maka pelatihan penyusunan soal OSCE perlu untuk diberikan kepada dosen pembimbing klinis. Hal ini menjadi dasar bagi penulis untuk memberikan pelatihan kepada dosen pembimbing klinis sebagai bentuk pengabdian penulis dalam membantu komunitas dan masyarakat.

\section{B. PELAKSAAAN DAN METODE}

Metode yang digunakan dalam pengabdian ini adalah dalam bentuk pelatihan. Pelatihan diberikan kepada dosen pembimbing klinis di RSU. Dr. Pirngadi Medan. Pelaksanaan pelatihan dilakukan melalui dua tahap, yaitu pemberian materi berupa dasar teori penyusunan soal OSCE, dan pelatihan penyusunan soal OSCE. Penyusunan soal OSCE dibimbing oleh satu fasilitator untuk setiap departemen. Masing-masing departemen diisi oleh 2-3 orang peserta dari departemen yang sesuai. Soal yang telah disusun akan di-review secara bersama dibawah bimbingan oleh penulis pertama. Pelaksanaan dilakukan selama 1 hari yaitu dimulai di pagi hari hingga sore hari.

Beberapa hari sebelum pelaksanaan pelatihan, fasilitator yang berjumlah 7 orang diberi pemahaman tentang prinsip-prinsip penulisan soal OSCE. Fasilitator merupakan anggota dari Medical Education Unit (MEU) yang juga familiar dan paham tentang pendidikan kedokteran.

Peserta pelatihan terlihat masih belum terbiasa dengan penyusunan soal OSCE. Agar memudahkan dalam menyusun soal, penulis menerapkan langkah-langkah tertentu dalam penyusunan soal. Langkah tersebut diawali dengan penentuan kasus penyakit yang akan dibuat menjadi soal OSCE. Kasus penyakit tersebut ditentukan berdasarkan SKDI (Standar Kompetensi Dokter Indonesia). Standar Kompetensi Dokter Indonesia disusun memiliki 4 level tingkatan yang menentukan kasuskasus penyakit yang dapat diterapi oleh seorang dokter (Konsil Kedokteran Indonesia, 2012a).

Langkah selanjutnya adalah menyusun skenario kasus penyakit tanpa harus mengikuti template soal OSCE. Skenario yang dibuat harus menyertakan seluruh pemeriksaan dan penatalaksanaan yang dibutuhkan dalam menangani kasus penyakit tersebut. Peserta pelatihan diminta mendiskusikan skenario kasus tersebut di masing-masing departemen agar terbentuk skenario yang baik.

Skenario kasus penyakit yang telah disusun kemudian dimasukkan ke dalam template soal OSCE. Pada langkah ini, bagian-bagian template yang tidak terisi karena tidak ada informasinya dalam skenario kasus penyakit kemudian ditambahkan. Penambahan informasi tersebut menyesuaikan dengan skenario penyakit. Informasi yang ditambahkan diantaranya adalah informasi tentang skenario Pasien Simulasi (PS), tipe tata letak ruangan, keterangan kebutuhan manekin, keterangan kebutuhan alat dan bahan, dan keterangan penggunaan laboran.
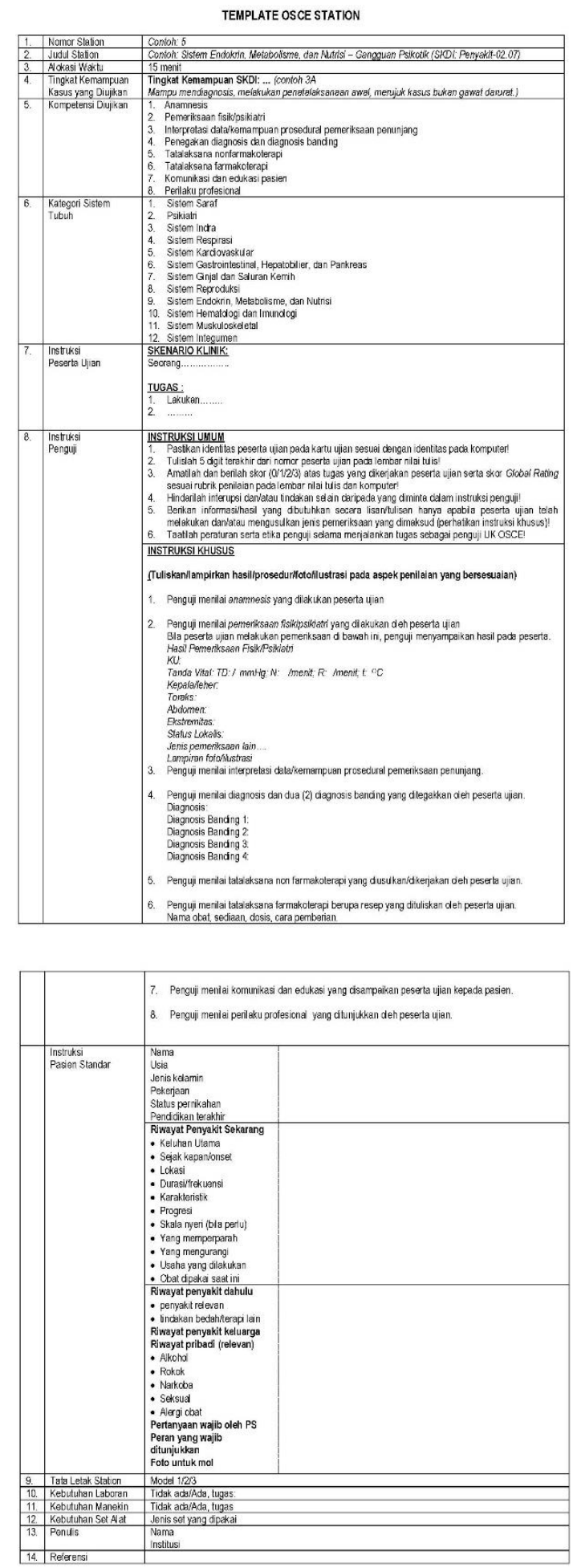

Gambar 1. Template Soal OCE 
Langkah penyusunan rubrik penilaian dilakukan dilakukan bila informasi soal telah terisi seluruhnya. Penentuan rubrik penilaian dilakukan dengan terlebih dahulu menentukan gambaran keterampilan dari masing-masing poin penilaian. Untuk poin penilaian " 3 ", peserta pelatihan diminta menentukan gambaran pelaksanaan keterampilan yang dinilai "baik". Selanjutnya menentukan poin penilaian "1" dengan menentukan gambaran pelaksanaan yang dinilai "buruk", dan terakhir menentukan poin penilaian "2" yaitu dengan menentukan gambaran pelaksanaan yang dinilai "cukup baik". Setelah seluruh poin penilaian ditentukan, maka peserta pelatihan diminta menentukan bobot dari masing-masing keterampilan yang diuji. Bobot penilaian diberikan sesuai dengan urutan keterampilan yang paling utama hingga pendukung sesuai dengan kasus skenario.

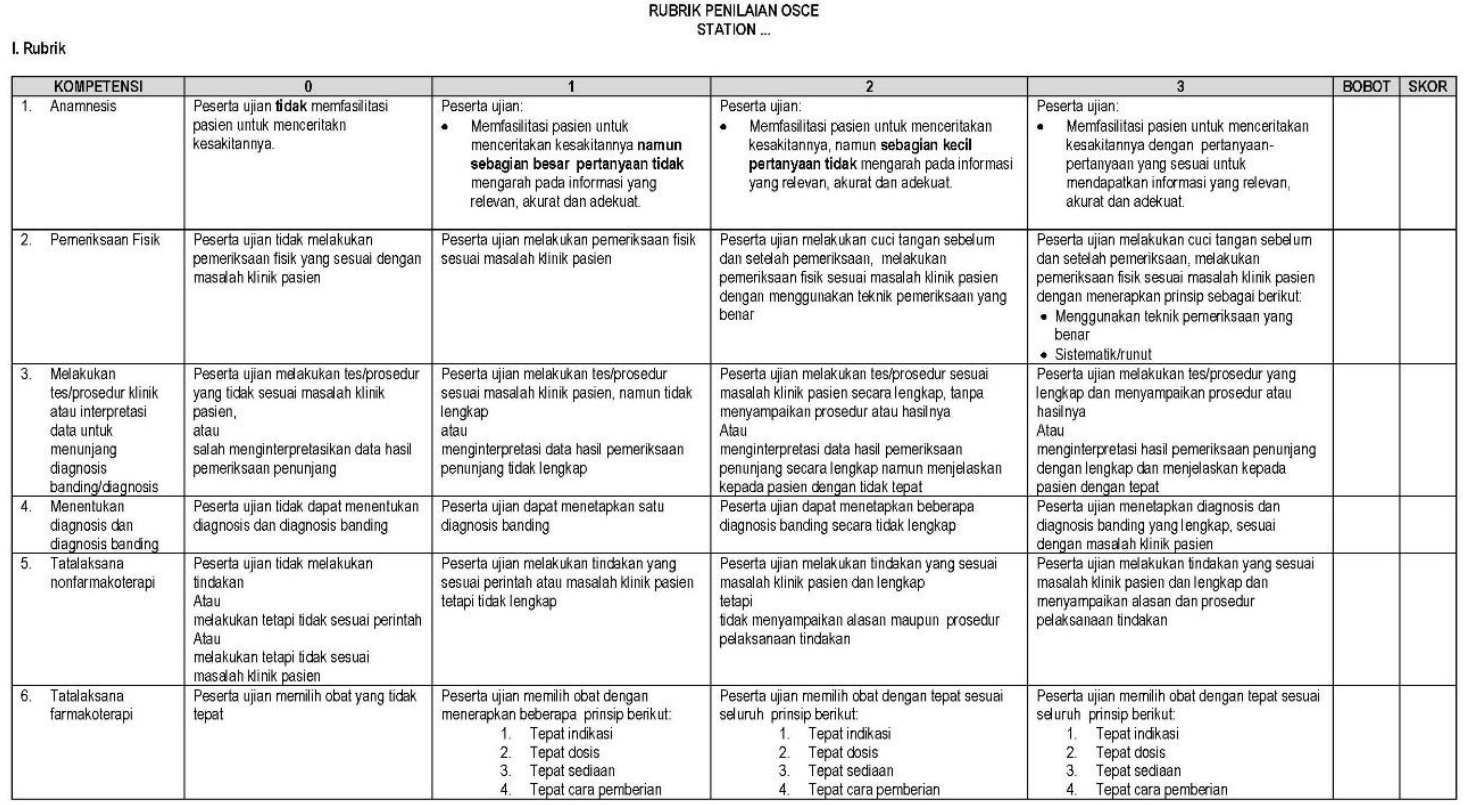

Gambar 2. Rubrik OSCE

\section{HASIL DAN PEMBAHASAN}

Pelatihan dihadiri oleh 15 orang dari 7 departemen yang berbeda. Departemen yang hadir pada pelatihan penyusunan soal OSCE adalah: departemen saraf, forensik, mata, kulit dan kelamin, bedah, kedokteran jiwa, paru. Peserta pelatihan secara antusias hadir di kedua sesi pelatihan.

Soal-soal yang diminta kepada peserta pelatihan tidak disusun berdasarkan blueprint soal. Hal ini dikarenakan fokus pelatihan lebih kepada bagaimana penyusunan soal OSCE dilakukan. Walaupun begitu, dalam materi blueprint tetap diberikan kepada peserta pelatihan.

Soal yang telah terkumpul di-review secara bersama dengan dibimbing oleh pemateri. Dari hasil proses review didapatkan seluruh soal diangkat dari kasus penyakit yang sesuai dengan level SKDI. Kasus yang diangkat sebaiknya dapat mengakomodir keseluruhan keterampilan yang akan dinilai (Daniels \& Pugh, 2018). Namun, dari ketujuh soal tersebut ada dua soal yang kurang sesuai antara tingkat penilaian dengan kasus penyakit di stasion tersebut. Soal tersebut adalah soal forensik dan soal kedokteran jiwa. Pada soal forensik dikatakan tidak sesuai karena kasus penyakit mengharuskan seorang dokter dapat menentukan jenis luka, dan memberikan keterangan Visum et Repertum (VeR) dari luka tersebut. Akan tetapi dari soal yang telah dibuat, peserta ujian hanya diminta merujuk pasien saja tanpa memberikan penilaian dan pelaporan VeR.

Soal kedokteran jiwa dinilai tidak sesuai antara tingkat penilaian dengan level SKDI karena pada SKDI kasus penyakit Skizofrenia hanya sampai level 3, yaitu hanya mampu memberi penatalaksanaan awal saja. Akan tetapi pada soal OSCE peserta ujian diminta untuk memberikan penatalaksanaan tuntas pada pasien. Keputusan terhadap kedua soal ini adalah perlu dilakukan revisi pada soal. Kejelasan penilaian menjadi hal yang penting agar penguji tidak ambigu dalam memberikan penilaian. Bahkan dapat dilakukan penyamaan persepsi kepada para penguji terkait poin penilaian yang diberikan (Daniels \& Pugh, 2018; Piumatti et al., 2021).

Penilaian terhadap kelengkapan soal berdasarkan template soal OSCE didapatkan secara umum seluruh soal telah memenuhi syarat tersebut. Hanya saja hampir seluruh soal tidak dilengkapi referensi, artinya penyusunan soal tidak mengikuti teori dan kaidah dalam penanganan kasus penyakit yang ada. Ada dua soal yang mencantumkan referensi soal, 
yaitu soal departemen kulit dan kelamin, dan departemen forensik.

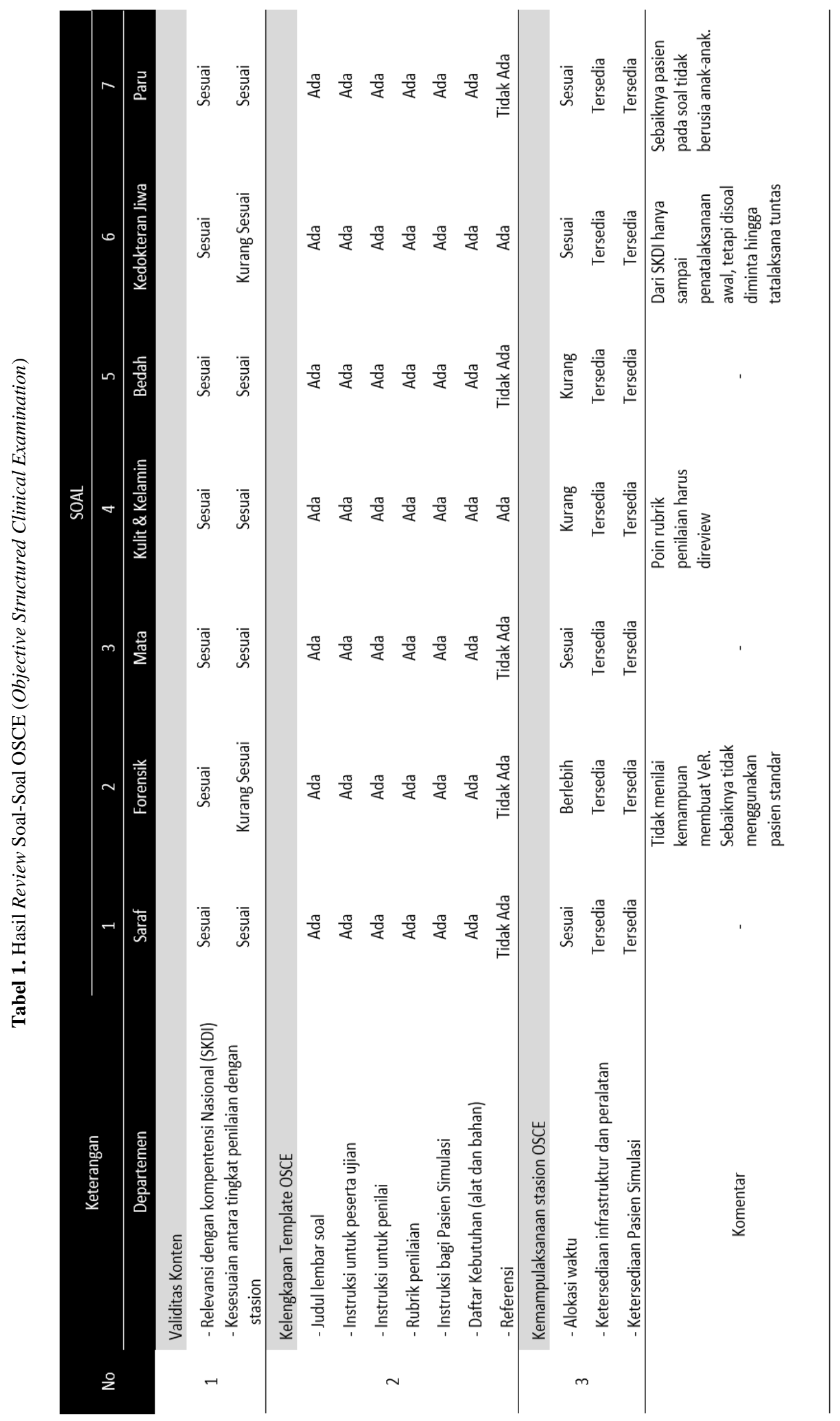


Alokasi waktu yang diberikan pada setiap stasionnya harus disesuaikan dengan banyaknya keterampilan yang diuji (Harden, 2015). Berdasarkan alokasi waktu yang disediakan dari soal OSCE dengan banyak dan kompleksnya keterampilan yang dilakukan, maka ada 1 soal yang memiliki alokasi waktu berlebih dan 2 soal yang memiliki alokasi waktu yang kurang. Alokasi waktu ujian berlebih ditemukan pada soal dari departemen forensik. Sedangkan alokasi waktu yang kurang didapatkan pada soal dari departemen kulit dan kelamin, dan soal dari departemen bedah.

\section{PENUTUP}

\section{Simpulan}

Penyusunan soal OSCE dapat dipermudah dengan menggunakan 4 langkah, yaitu: menentukan kasus penyakit sesuai level kompentesi SKDI, menyusun skenario sesuai dengan kasus penyakit yang telah ditentukan, memasukkan skenario ke dalam template soal OSCE, melengkapi informasi dari template soal dan rubrik penilaian. Menggunakan langkah-langkah tersebut peserta pelatihan terbukti memudahkan dosen pembimbing klinis dalam menyusun soal OSCE.

Soal yang telah disusun sebaiknya di-review tidak hanya oleh pakar dari departemen yang sama namun juga oleh orang yang memiliki kemampuan dan pengalaman dalam me-review soal OSCE. Adanya pakar lain dari departemen yang sama berguna untuk me-review konten (teoritis) dari soal OSCE, sedangkan kehadiran orang yang berpengalaman me-review soal OSCE (struktur soal) diperlukan untuk memastikan kelengkapan informasi dari soal OSCE tersebut.

\section{Saran}

Menyusun soal OSCE sebaiknya dilakukan secara bersama-sama dengan melibatkan penyusun soal yang sudah berpengalaman dengan yang belum berpengalaman. Review soal OSCE sebaiknya disertai dengan simulasi pelaksanaan ujian OSCE menggunakan soal yang telah disusun, hal ini untuk mengantisipasi kekurangan informasi yang mungkin terjadi pada soal OSCE.

\section{E. DAFTAR PUSTAKA}

Anderson, L. W., Krathwohl, D. R., \& Bloom, B. S. (2001). A taxonomy for learning, teaching, and assessing: a revision of Bloom's taxonomy of educational objectives. 41(4), 352.

http://books.google.com/books?id=JPkXAQ AAMAAJ\&pgis $=1$

Boursicot, K., \& Roberts, T. (2005). Hot to set up an OSCE. The Clinical Teacher, 2(1), 16-20.
Daniels, V. J., \& Pugh, D. (2018). Twelve tips for developing an OSCE that measures what you want. Medical Teacher, 40(12), 1208-1213. https://doi.org/10.1080/0142159X.2017.1390 214

Dent, J. A., \& Harden, R. M. (2013). A Practical Guide for Medical Teacher 4th edition (fourth). Churchill Livingstone Elsevier. https://doi.org/10.1360/zd-2013-43-6-1064

Elshama, S. S. (2020). How to Design and Apply an Objective Structured Clinical Examination (OSCE) in Medical Education? Iberoamerican Journal of Medicine, 1, 51-55. https://doi.org/10.5281/zenodo.4247763.1.

Harden, R. M. (2015). Misconceptions and the OSCE. Medical Teacher, 37(7), 608-610. https://doi.org/10.3109/0142159X.2015.1042 443

Khan, K. Z., Gaunt, K., Ramachandran, S., \& Pushkar, P. (2013). The Objective Structured Clinical Examination (OSCE): AMEE Guide No. 81. Part II: Organisation \& Administration. Medical Teacher, 35(9), 142159. https://doi.org/10.3109/0142159X.2013.8186 35

Konsil Kedokteran Indonesia. (2012a). Standar Kompetensi Dokter Indonesia Konsil Kedokteran Indonesia (Kedua). Konsil Kedokteran Indonesia. http://www.kki.go.id/assets/data/arsip/SKDI_ Perkonsil,_11_maret_13.pdf

Konsil Kedokteran Indonesia. (2012b). Standar pendidikan profesi dokter (Kedua). Konsil Kedokteran Indonesia.

Konsil Kedokteran Indonesia. (2013). Salinan Peraturan Konsil Kedokteran Indonesia Nomor 12 Tahun 2013 Tentang Penerapan Kerangkan Kualifikasi Nasional Indonesia Untuk Pendidikan Kedokteran.

Krathwohl, D. ., Bloom, B. ., \& Masia, B. . (1964). Taxonomy of educational objectives: The classification of educational goals Handbook II: Affective Domain. David McKay Company. http://scholar.google.co.uk/scholar?start=0\&q =bloom+krathwohl\&hl=en\&lr=lang_en\&as_s $\mathrm{dt}=0,5 \# 8$

Miller, G. E. (1990). The assessment of clinical skills/competence/performance. Academic Medicine, 65(9), S63-S67. https://doi.org/10.1097/00001888199009000-00045

Patwari, R., Ferro-Lusk, M., Finley, E., \& Meeks, L. M. (2021). Using a Diagnostic OSCE to Discern Deficit From Disability in Struggling Students. Academic Medicine, 96(2), 228231.

https://doi.org/10.1097/ACM.000000000000 3421

Piumatti, G., Cerutti, B., \& Perron, N. J. (2021). 
Assessing communication skills during OSCE: need for integrated psychometric approaches. BMC Medical Education, 21(106), $1-10$. https://doi.org/10.1186/s12909-021-02552-8

Singh, G., \& Singh, R. (2020). Domains of Learning: Art of Learning in Medical Education Program. Era's Journal of Medical
Research,

$7(1)$,

$1-7$. https://doi.org/10.24041/ejmr2020.14

Tyas, M. A., Nurkamto, J., \& Marmanto, S. (2020). Cultivating Students ' Higher -Order Thinking Skills in EFL Classes: The Role of the Teacher and The Textbook. International Online Journal of Education and Teaching, 7(1), 267-276. 